\title{
Evaluation on Heat Transferring Performance of Fabric Heat Sink by Finite Element Modeling
}

\author{
Huashuai Zhang1, Jiyong Hu1,2, Xudong Yang1,2, Yuling $\mathrm{Li}^{2}$ \\ ${ }^{1}$ Engineering Research Center of Technical Textiles, Ministry of Education, Donghua University, Shanghai, \\ China \\ ${ }^{2}$ Key Laboratory of Textile Science \& Technology, Ministry of Education, Donghua University, Shanghai, \\ China \\ Email: hujv@dhu.edu.cn
}

Received 13 February 2015; accepted 16 March 2015; published 24 March 2015

Copyright (C) 2015 by authors and Scientific Research Publishing Inc.

This work is licensed under the Creative Commons Attribution International License (CC BY).

http://creativecommons.org/licenses/by/4.0/

(c) (i) Open Access

\begin{abstract}
Considering current technology limitation in manufacturing present pin fin heat sinks, a new fabric heat sink has been previously designed. However, there is a lack of an understanding of the heat transferring performance of this new kind of heat sink. Nowadays, finite element analysis has been generally developed for determining heat transfer from in-line and staggered pin fin heat sinks used in electronic packaging applications. In this study, this method is used to predict the heat transfer performance of the new heat sink with woven fabric structure, called fabric pin fin heat sink. Effect of the fin length and the material types made of heat sink on the thermal-structure response of the pin fin was investigated under forced convection. The results show that the minimum temperature of heat sink decreases with an increase of pin fin length, but the decreasing amplitude has decreased. Moreover, the heat transfer performance of fabric heat sink made of continuous carbon Fibers/Polymer (PPS) is worse than that of copper and of aluminum.
\end{abstract}

\section{Keywords}

Heat Sink, Woven Fabric, Pin Fin, Temperature

\section{Introduction}

Due to the low cost and high reliability, pin fin heat sinks are broadly used for thermal management of various applications. Accordingly, very extensive literatures exist on the subject [1] [2]. At the same time, the reasons of 
miniaturized applications have forced design engineers to seek more efficient heat sink technologies. One of the more powerful cooling technologies that have emerged in recent years is the pin fin technology. The unique pin fin design generates significant cooling power and is highly suitable for "hot" heat sources and applications that have limited space for cooling [3]. Fabric heat sink, as shown in Figure 1 is a radiator similar to pin fin heat sink in structure, whereas the specific surface area is bigger than the common pin fin heat sink. In theory, the heat transfer performance is better. However, the specific heat transferring performance of fabric heat sink is still unknown.

Pin fin heat sinks for surface mount heat sources are available in a variety of configurations, sizes and materials. Wirtz et al. reported experimental results on the thermal performance of model pin fin fan-sink assemblies. They used cylindrical, square, and diamond-shaped cross-sectional pin fins and found that cylindrical pin fins give the best overall fan-sink performance. Furthermore, the overall heat-sink thermal resistance decreases with an increase in either pressure rise or fan power and fin height [3]. Sparrow et al. carried out an experimental study on combined-mode natural convection/radiation heat transfer characteristics of common arrays of pin fins, and the effect of various parameters on the thermal performance was investigated. It was found that thermal performance increased with fin length. Their study revealed the existence of an optimum number of fins for a fixed base plate size. The length, while there seems to be a point of diminishing return with respect to the increasing fin length [4]. Khan et al. examine the effect on overall thermal fluid performance associated with different fin geometries, materials and the combine combined effect of thermal resistance and pressure drop. They found that as the thermal conductivity of the material increases and more slender pin will be required for copper fin than a composite plastic fin [5]. Sarma et al. compared the heat transfer performance of a standard pin fin, splayed pin fin and hybrid pin fin heat sinks through CFD modeling and simulations. They found hybrid pin fin heat sinks promise to keep electronic circuits $20 \%$ to $40 \%$ cooler than standard pin fin heat sinks [6].

However, there are several intrinsic differences between the fabric heat sink and the common pin fin heat sink. The base plate of fabric heat sink is woven fabric structure, not the compact homogenous structure of pin fin heat sink. Moreover, the heat transferring elements of fabric heat sink is loop yarns and consisted of a continuous yarn for each row. So it needs to carry out an analysis on the heat transferring performance of fabric pin fin heat sink. In the present study, a finite element model of fabric heat sink was built. And the model was used to explore the effect of the fin length and various fabric pin fin (the combination of pin fin and base fabric) materials on the thermal-structure response of the fabric heat sink has been investigated for force convection numerically.

\section{Modeling and Methods}

\subsection{Physic Modeling}

The structure of fabric heat sink is shown in Figure 2(a). For comparison, the configuration of a common pin fin heat sink is illustrated in Figure 2(b). The geometrical model consists of the continuous loop yarn as heat transferring pin fins (hereafter, referred to fabric pin fins) and the pin fins carrier fabric. Fabric pin fins are fixed to the carrier fabric, and it is just like the pin fin fixed on the base plate in Figure 2(b). The carrier fabric can be fabricated by the plain, twill and satin texture. There, the twill (3/1) texture is simulated, and the weaving parameters are shown in Table 1.

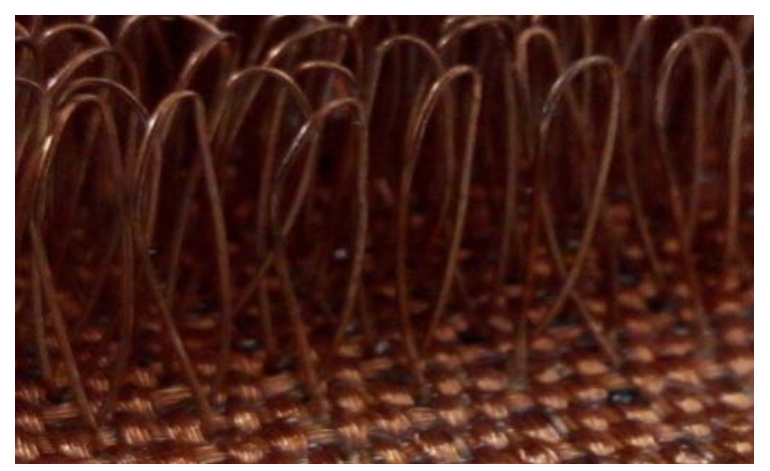

Figure 1. Fabric heat sink. 


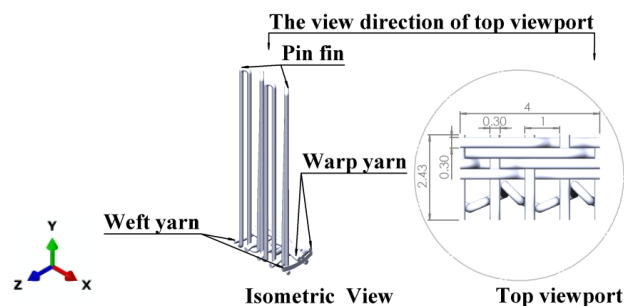

(a)

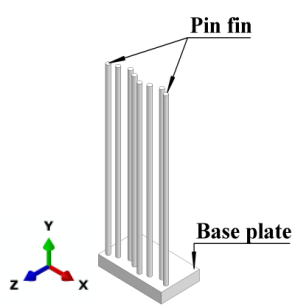

(b)

Figure 2. The geometry of fabric structure heat sink. (a) Pin fin heat sink; (b) Fabric heat sink.

Table 1. Geometry of twill (3/1) texture.

\begin{tabular}{|cccccc|}
\hline \multicolumn{2}{|c}{ Diameter } & \multicolumn{2}{c}{ Thread spacing } & \multicolumn{2}{c|}{ Unit cell spacing } \\
\hline Warp yarn $(\mathrm{mm})$ & Weft yarn $(\mathrm{mm})$ & Warp yarn $(\mathrm{mm})$ & Weft yarn $(\mathrm{mm})$ & Warp yarn $(\mathrm{mm})$ & Weft yarn $(\mathrm{mm})$ \\
\hline $\mathbf{0 . 3}$ & 0.3 & 0.3 & 1 & 2.43 & 4 \\
\hline
\end{tabular}

\subsection{Heat Transferring Principles}

According to the basic theory of heat transfer [7], the temperature distribution along the axial of single pin fins could be expressed as

$$
\begin{aligned}
& \frac{\partial^{2} t}{\partial x^{2}}+\frac{\partial^{2} t}{\partial y^{2}}+\frac{\partial^{2} t}{\partial z^{2}}=0 \\
& -\lambda\left(\frac{\partial t}{\partial n}\right)_{w}=h\left(t_{w}-t_{f}\right) \\
& -\lambda \frac{\partial T}{\partial n}=\varepsilon \sigma\left(T_{w}^{4}-T_{e}^{4}\right)
\end{aligned}
$$

where $t$ is the temperature, $\lambda$ is the thermal conductivity, $x, y, z$ are the Cartesian coordinate, $n$ is the outer surface normal direction, $h$ is the convective heat transfer coefficient, $t_{w}$ is the temperature of the surface, $t_{f}$ is the temperature of fluid, $t_{e}$ is the temperature of environment, $\varepsilon$ is the emissivity, $\sigma$ is the Stefan-Boltzmann constant. The heat flux $q$ is used to express the heat transfer rate, and a large value of $q$ means well heat transfer performance.

\subsection{Numerical Analysis}

Before a numerical analysis is performed, the following assumptions are made:

1) There are no heat sources within the fin itself.

2) The temperature at the base of the heat source is uniform.

3) The fin material is homogeneous.

4) The role of air is replaced by convective heat transfer coefficient.

5) The angle between pin fin and the horizontal plane is constant.

6) The sections of the model are considered to be adiabatic.

To evaluate the heat transferring performance of fabric heat sink, this work will simulate the case that the fabric heat sink was heated by a heating plate. The interface between fabric heat sink and the heating plate is filled by thermal conductive silicone. Additionally, the carrier fabric was filled into the thermal conductive silicone. In this way, the heating plate, as the heat source, thermal conductive silicone and the fabric heat sink was a simulation ensemble. Based on the above assumption and the simulation environment, a finite element model (FEM) was established, as shown in Figure 3(b). For comparison, the physic model of pin fin heat sink is shown in Figure 3(a). In the model the heat source is modeled by cuboids. The FEM of heat sinks are made by ABAQUS software. In order to ensure the accuracy of the calculation element type of the heat source is DC3D20, and the other parts of the model is DC3D10. 


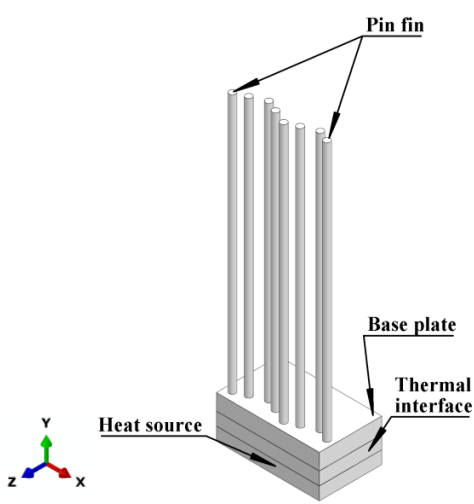

(a)

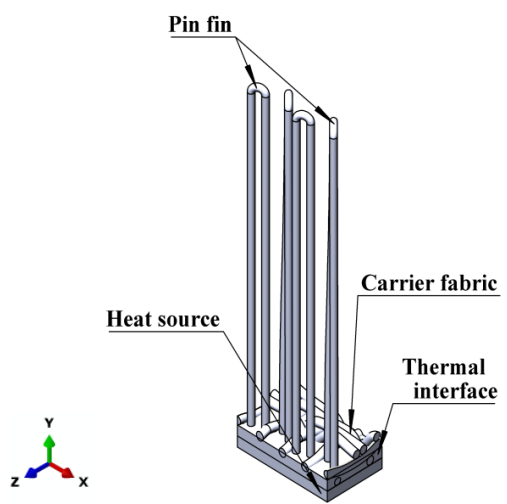

(b)

Figure 3. Geometrical ensemble of heat sink and heat source in the simulation. (a) Pin fin heat sink; (b) Fabric heat sink.

According to the discussion in the introduction section, the effect of fin length and various fabric pin fin (the combination of pin fin and base fabric) materials on the thermal-structure response of the pin fin has been investigated for force convection. For simplicity, the force convection is modeling as the $h=0.2 \mathrm{~mJ} /\left(\mathrm{mm}^{2} \cdot \mathrm{K}\right)$ (a typical forced air convection value) [8]. The parametric values for geometry, thermal and structural-boundary conditions in the simulation are listed in Table 2. For modeling purpose, the temperature at the bottom of the heat source keeps $t_{\mathrm{HSB}}=95^{\circ} \mathrm{C}$. The material properties of fabric heat sink and heat source are listed in Table 3 .

From the finite element modeling, the temperature distribution along the axial (pin fin) direction is calculated, and the heat flux, the heat flow per unit time through unit area, $q\left(\mathrm{~mJ} / \mathrm{mm}^{2}\right)$, is derived.

\section{Results and Discussion}

\subsection{Heat Transferring}

The new heat sink, i.e. fabric heat sink was inspired by the common pin fin heat sink. Firstly, a comparative analysis of common pin fin heat sink and fabric pin fin heat sink is shown in Figure 4 and Figure 5. Apparently, the temperature distribution between the model of pin fin and fabric pin fin heat sinks are similar in Figure 4.

Specifically, the temperature distribution along axial direction for pin fin and fabric heat sink is shown in Figure 5. It can be seen that temperature decreases with the increase of pin fin length. The temperature of pin fin heat sink is lower than fabric heat sink's at the root of pin fin, while it is higher than fabric heat sink's with the increase of pin fin length up to $L=0.5 \mathrm{~mm}$. The reason of the phenomenon is that the root of pin fin of the pin fin heat sink has been surrounded by base plate.

\subsection{Fin Length Effect}

In this study, the effect of five different lengths of pin fin for fabric pin fin heat sink on the heat transferring has been investigated. The temperature change along the pin fin axis is shown in Figure 6. It could be found that temperature has rapidly decreased along the axial direction of pin fin. The difference between curves of $L=10$ and $L=15$ is well pronounced. However, the difference is getting smaller with the increase of pin fin length, and curves between $L=20, L=25$ and $L=30$ almost coincide.

\subsection{Pin Fin Material Effect}

In this study, three difference combinations of materials were selected for the fabric pin fin, thermal-interface and heat source, respectively, have been considered. The reason for PPS was selected is that thermally conductive composites as compared to metals have reduced density, decreased oxidation, and improved chemical resistance, as well as adjustable properties to fit a given application [9]. And the heat transfer performance of fabric heat sink made of PPS should be considered in the study as an assumption. Figure 7 shows that the temperature of the pin fin increases at the initial time and then followed a thermal equilibrium over a long time. However, it could be found that the fabric pin fin material with PPS needs the shortest time to increase the temperature of 


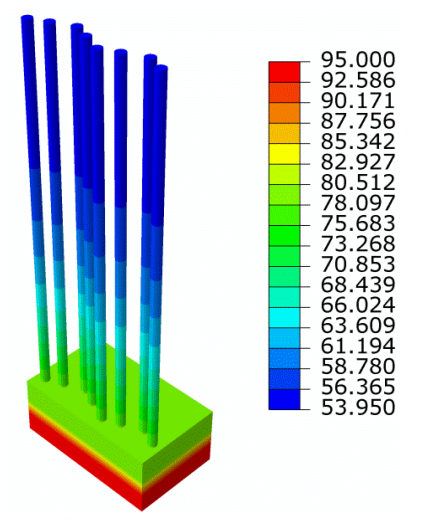

(a)

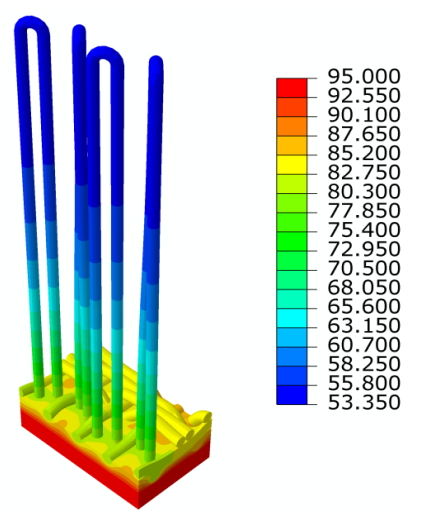

(b)

Figure 4. Temperature distribution for pin fin and fabric heat sink (Unit: ${ }^{\circ} \mathrm{C}$ ). (a) Pin fin heat sink; (b) Fabric heat sink.

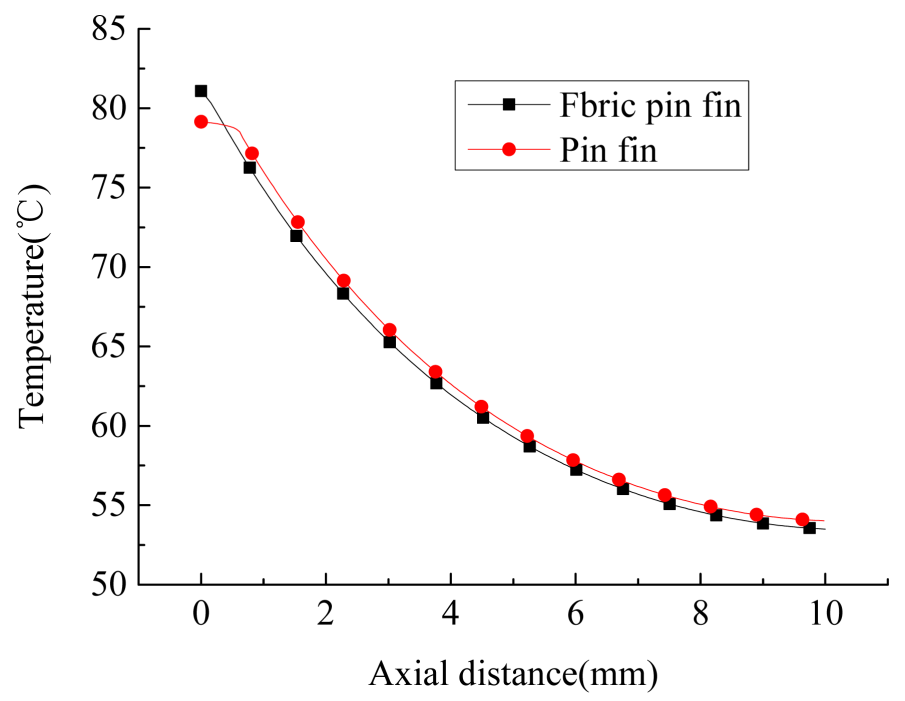

Figure 5. Temperature distribution along axial direction of pin fin.

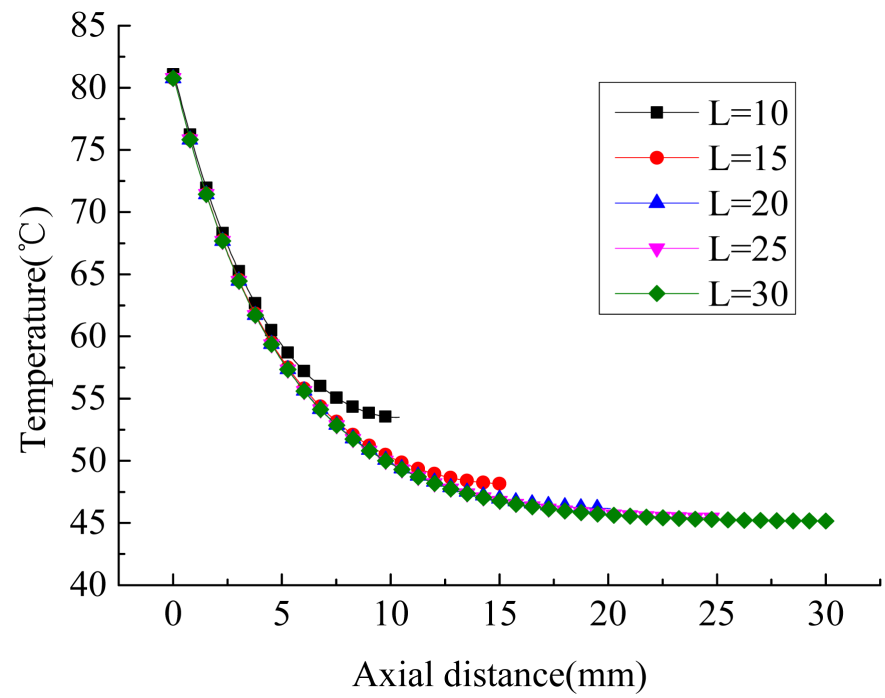

Figure 6. Temperature distribution along axial direction of pin fin. 


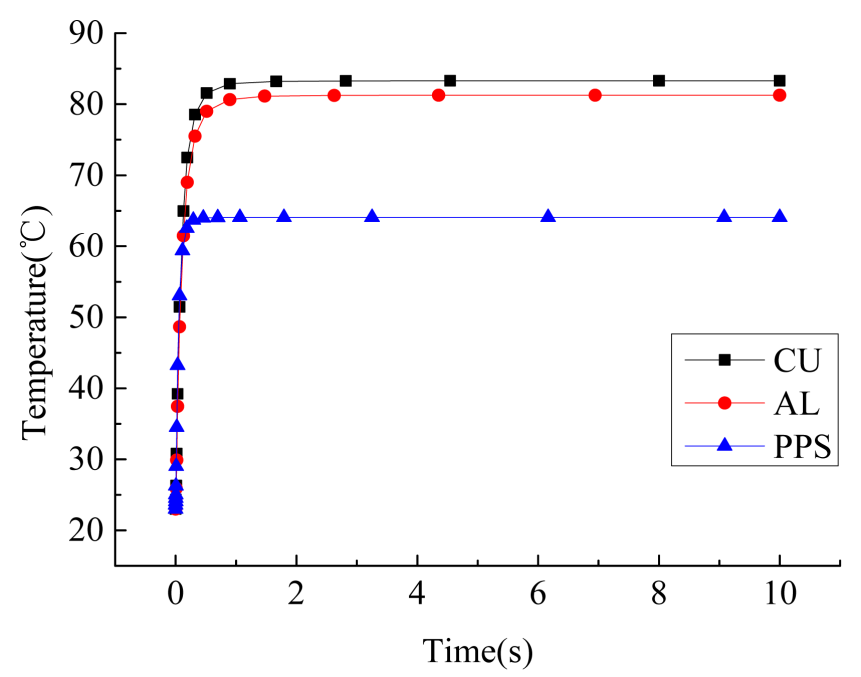

Figure 7. Temperature change for AL, CU, PPS in the case of $L=30$.

Table 2. Parametric values for geometric and thermal boundary conditions.

\begin{tabular}{|c|c|}
\hline Geometry & Values \\
\hline Fin radius & $R=0.125 \mathrm{~mm}$ \\
\hline Fin length & $L=10 \mathrm{~mm}, 15 \mathrm{~mm}, 20 \mathrm{~mm}, 25 \mathrm{~mm}, 30 \mathrm{~mm}$ \\
\hline Carrier fabric & Twill weaves \\
\hline \multicolumn{2}{|l|}{ Thermal boundary condition } \\
\hline Sink temperature & $t_{\infty}=45^{\circ} \mathrm{C}$ \\
\hline Convective heat transfer coefficient & $h=0.2 \mathrm{~mJ} /\left(\mathrm{mm}^{2} \cdot \mathrm{K}\right)$ \\
\hline Heat source bottom temperature & $t_{\mathrm{HSB}}=95^{\circ} \mathrm{C}$ \\
\hline
\end{tabular}

Table 3. Thermal properties of materials.

\begin{tabular}{|c|c|c|c|c|c|c|}
\hline Material & Type & $\begin{array}{l}\text { Density } \\
\left(\mathrm{t} / \mathrm{mm}^{3}\right)\end{array}$ & \multicolumn{2}{|c|}{$\begin{array}{l}\text { Conductivity } \\
\left(\mathrm{mJ} / \mathrm{mm} \cdot{ }^{\circ} \mathrm{C}\right)\end{array}$} & $\begin{array}{c}\text { Specific Heat } \\
\left(\mathbf{m J} / \mathbf{t}^{\circ} \mathrm{C}\right)\end{array}$ & Emissivity \\
\hline Copper & Isotropic & $8.80 \times 10^{-9}$ & \multicolumn{2}{|c|}{287} & $3.76 \times 10^{8}$ & 0.07 \\
\hline Aluminum (Al-6063) & Isotropic & $2.7 \times 10^{-9}$ & \multicolumn{2}{|c|}{218} & $9.00 \times 10^{8}$ & 0.05 \\
\hline \multirow[t]{2}{*}{ Continuous carbon Fibers/Polymer (PPS) } & Orthotropic & $1.8 \times 10^{-9}$ & Longitudinal & Transverse & $8.88 \times 10^{8}$ & 0.8 \\
\hline & & & 330 & $3-10$ & & \\
\hline Thermal conductive silicone (SC8101) & Isotropic & $1.97 \times 10^{-9}$ & 4. & & $1.43 \times 10^{9}$ & -- \\
\hline
\end{tabular}

pin fin, i.e. the heat has the fast heat transferring rate from the heat source to the base of pin fins. It is very important for this fast heat transferring rate to protect the key element of electrical applications.

To compare the specific difference between the heat transferring rate, Figure 8 shows the heat flux of the pin fin variation over time. The heat flux of CU and AL increased to a maximum in a short time and decreased until the balance slowly, while the curve of PPS hasn't decreased process. It could be found that $q_{\mathrm{CU}}>q_{\mathrm{AL}}>q_{\mathrm{PPS}}$.

Due to the similar thermal properties of copper and aluminum, the heat transfer performance is similar with each other. However, the difference between them and PPS is significant. The minimum and maximum temperature differences between them are plotted in Figure 9. It is found that the fabric heat sink with pin fin of AL has the largest temperature difference. The temperature difference for PPS is bigger than CU and AL. 


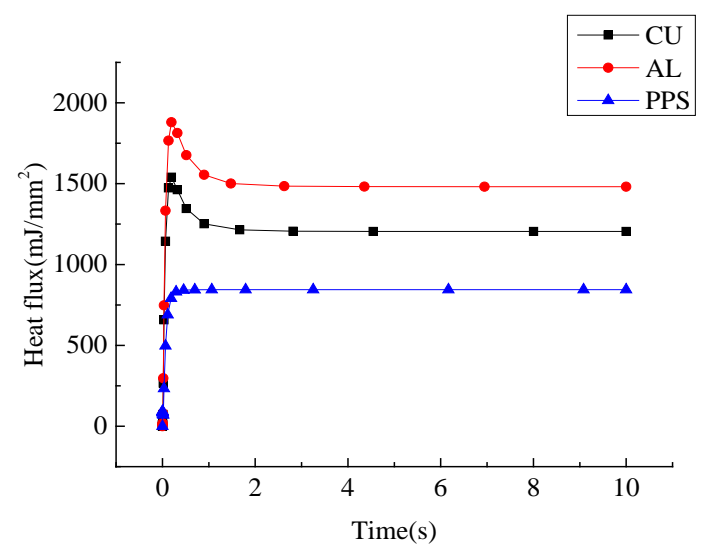

Figure 8. Heat fluxof $L=30$ for AL, CU, PPS.

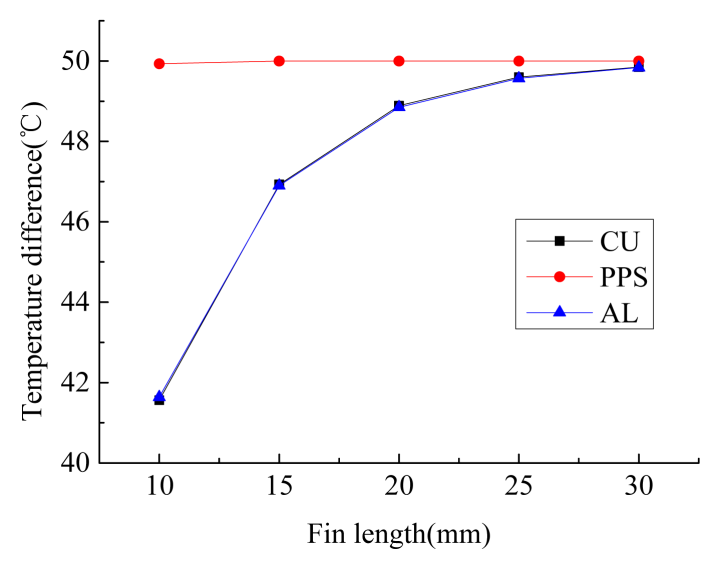

Figure 9. Temperature difference for various materials.

\section{Conclusions}

The fabric heat sink is manufactured by traditional woven technology, and its heat transferring performance has some difference from the common pin fin heat sinks.

The thermal performance of the fabric heat sink is improved when fin length is increased, while there is a little of diminishing return with respect to increasing fin length. Meanwhile, the heat transfer performance of radiator made by PPS is worse than both CU and AL.

\section{Acknowledgements}

This work is supported by the Fundamental Research Funds for the Central Universities.

\section{References}

[1] Kraus, A.D., Aziz, A. and Welty, J. (2002) Extended Surface Heat Transfer. John Wiley \& Sons, Hoboken.

[2] Shabany, Y. (2010) Heat Transfer. CRC Press, Boca Raton.

[3] Wirtz, R., Sohal, R. and Wang, H. (1997) Thermal Performance of Pin Fin Fan-Sink Assemblies. Journal of Electronic Packaging, 119, 26-31. http://dx.doi.org/10.1115/1.2792197

[4] Sparrow, E. and Vemuri, S. (1985) Natural Convection/Radiation Heat Transfer from Highly Populated Pin Fin Arrays. Journal of Heat Transfer, 107, 190-197. http://dx.doi.org/10.1115/1.3247377

[5] Kobus, C.J. and Oshio, T. (2005) Development of a Theoretical Model for Predicting the Thermal Performance Characteristics of a Vertical Pin fin Array Heat Sink under Combined Forced and Natural Convection with Impinging Flow. International Journal of Heat and Mass Transfer, 48, 1053-1063.

http://dx.doi.org/10.1016/j.ijheatmasstransfer.2004.09.042 
[6] Khan, W.A. (2004) Modeling of Fluid Flow and Heat Transfer for Optimization of Pin fin Heat Sinks. Ph.D. Dissertation, Mechanical Engineering, Citeseer.

[7] Anusha, I.L., et al. (2014) CFD Analysis of Splayed Pin Fin Heat Sink Using Advanced Composite Materials. International Conference on Advances in Mechanical Sciences, 493-495.

[8] Incropera, F.P. (2011) Introduction to Heat Transfer. John Wiley \& Sons, Hoboken.

[9] Arif, A.F.M., Zubair, S.M. and Pashah, S. (2012) Thermal-Structural Performance of Orthotropic Pin Fin in Electronics Cooling Applications. Journal of Electronic Packaging, 134, Article ID: 041005.

http://dx.doi.org/10.1115/1.4007258 